\title{
Postura ética e jurídica do engenheiro de produção
}

Dener Martins dos Santos

Professor Doutor UBM e Professor Adjunto da UERJ

ORCID: http://orcid.org/0000-0002-4454-1779

E-mail: dener.santos@uerj.br

\section{Paulo Cuconato}

Mestre em Direito, Pós-graduado em Psicologia Jurídica e Mediador Judicial

ORCID: http://orcid.org/0000-0003-2199-9055

E-mail: cucopaulo@gmail.com 


\section{Resumo}

Este trabalho tem como objetivo apresentar um estudo das imbricações decorrentes do processo decisório que permeia uma gama de aptidões que o engenheiro de produção deve possuir, ao lidar com os colaboradores em uma equipe multiprofissional de trabalho. A metodologia utilizada consistiu na análise da conduta ética e profissional, envolvendo os vários segmentos dos saberes: psicologia, direito e tecnológico. Unidos na manutenção do comportamento emocional do engenheiro na conformidade da plenitude do exercício profissional, ao transmitir por meio de comunicações, comandos e conhecimentos para todos os membros da equipe de colaboradores. Isso deve ocorrer através de diálogo claro por meio de comunicação edificante, a fim de preservar as condições emocionais e psicológicas tanto de quem as emite quanto de quem as recebe; na promoção e garantia das boas práticas laborais. Neste trabalho se concluiu que no rol de condutas que abarcam a profissão do engenheiro de produção, este perpassa por diferentes segmentos científicos como a própria psicologia jurídica presente neste viés híbrido da psicologia com o judiciário. Ao considerar os conflitos que podem advir dessas inúmeras situações profissionais e interpessoais, diante da complexidade da natureza humana. Muitas vezes oriundas de um processo ruidoso e/ou falho de comunicação que conduzem a diversas implicações legais que podem chegar até a judicialização dessas atividades profissionais.

Palavras-Chave: Aspectos Éticos e Jurídicos, Comunicação, Engenharia de Produção.

\section{Abstract}

This work aims to present a study of the imbrications resulting from the decisionmaking process that permeates a range of skills that the production engineer must possess, when dealing with employees in a multiprofessional work team. The methodology used consisted of the analysis of ethical and Professional conduct involving the various segments of knowledge: psychology, Law and technology. It joined to keep engineer emotional behavior in conformity with the fullness of professional practice, by transmitting through communications, commands and knowledge to all work team. This occurs through clear dialogue for uplifting communication, to preserve the emotional and psychological conditions of both those who send them and those receive them, promoting and guaranteeing good work practices. It was concluded that encompass conducts list the production engineer profession; this goes through different scientific segments such as the legal psychology itself present in this hybrid bias of 
psychology with the judiciary. When considering the conflicts that arise from numerous professional and interpersonal situations due the human nature complexity. Often coming from a noisy and/or failed communication process that lead to several legal implications that goes as far as the judicialization of these professional activities.

Key words: Ethical and Legal Aspects, Communication and Production Engineering.

\section{Introdução}

Todos os saberes de diferentes áreas científicas do conhecimento humano dialogam e entrelaçam entre si; mesmo aqueles que aparentemente estão alocados em grupos bem definidos, como por exemplo: humanas, tecnológicas e saúde. Isso advém das mudanças sociais, políticas e econômicas; e, também do movimento de acesso à justiça, ora observados e vivenciados, principalmente a partir do último século (CUCONATO, 2016). Nessa confluência de conhecimentos, todos os profissionais necessitam de habilidades e competências múltiplas para transitar em diferentes espectros do comportamento humano, de modo ético e eficaz.

No caso da engenharia de produção, este tipo de engenheiro, na plenitude do exercício profissional, em sua lida diária, tanto no desenvolvimento de pesquisa científica quanto da aplicação de tais conhecimentos no chão de fábrica, precisa tomar decisões, às vezes imediatas e outras nem tanto, contudo estas devem ser embasadas técnica e juridicamente junto aos colaboradores. Tais ações ocorrem de forma acelerada e se entrelaçam diante dos vários espectros de interesses ligados à empresa e à sociedade onde o principal ator é o ser humano.

Os aspectos comportamentais influenciam diretamente no desenvolvimento profissional dos colaboradores, pois as ações destes podem demonstrar se eles se adaptaram ou não à cultura da empresa, pois as estruturas 
hierarquizadas dos ambientes de trabalho, a globalização de produtos e serviços e o rápido desenvolvimento tecnológico, hoje observado, tornaram cada vez mais os ambientes corporativos, dinâmicos, adaptativos e flexíveis às diversas tendências do mercado; necessário para as empresas que desejam se manter vivas e competitivas.

Desde o início século $X X$, há relatos a respeito do surgimento e evolução de uma nova sociedade sedenta de justiça e ansiosa por seus direitos, que clamava por melhores resultados de suas pretensões resistidas tais como: acessibilidade a bens de consumo, direitos fundamentais, e relacionamento inter e intrapessoal com parcimônia tanto no ambiente de trabalho quanto na sociedade (BOBBIO, 2009).

Dessa forma, Leis trabalhistas, sociais e penais mais eficazes, proporcionaram maior contemplação das partes envolvidas em um conflito; seja ele relacionado a bens de consumo produzidos inadequadamente, seja diante de interesses de um melhor e mais saudável ambiente de trabalho.

Atualmente, as pessoas, quando não conhecem a fundo todos os preâmbulos jurídicos que podem entrelaçar as relações no ambiente de trabalho, possuem uma vaga ideia destas; ou a quem e onde recorrer. A multiplicidade de conhecimento, ora experimentada através da oferta de diferentes meios de informação e a influência da globalização, permitiu aos colaboradores em uma empresa acessar e possuir conhecimentos que anteriormente pertenciam a grupos específicos de profissionais (OLIVEIRA JÚNIOR, 2010), de acordo com a sua respectiva área de formação acadêmica, ou em alguns casos, devido à longínqua experiência acumulada em vários anos dedicados exaustivamente à prática profissional.

Contudo, hoje em dia, a grande maioria das pessoas habita na era da informação e essas confluências de conhecimentos díspares devem ser tratadas, 
com parcimônia e precaução, por aqueles que possuem cargos de tomadas de decisão, diante as várias variáveis que podem ser acopladas em somente um único lócus de ação.

\section{OBJETIVO}

O objetivo deste artigo trata-se de realizar uma reflexão sobre o papel do engenheiro de produção frente a algumas das mais recorrentes questões que abarca o perfil dessa profissão, bem como a legalidade do seu exercício profissional.

Os aspectos tratados neste artigo relacionam-se àquelas posturas éticas frente a situações de elevado estresse emocional no qual este não pode se distanciar dos fundamentos técnicos e jurídicos relevantes em suas proposições. Diante disso, há a necessidade de observação do perfil psicológico de todos os agentes envolvidos no ambiente de trabalho, para a autoconstrução de uma postura e de uma verbalização da situação, embasada tecnologicamente para que não entre em embates desgastantes e infrutíferos, o que culminará em um baixo rendimento da equipe de colaboradores diante das tarefas propostas, mediante o regime de trabalho imposto.

\section{Fundamentação Teórica}

\section{HISTÓRICO DA PROFISSÃO DE ENGENHEIRO}

A regulamentação da profissão de engenheiro, no Brasil, ocorreu pelo Decreto número 23.569 de 1933 e atualizada pela Lei 5194 de 1966 e referendada pelas Resoluções do Conselho Federal de Engenharia (CONFEA) 218/1973, 235/1975, 288/1983 e 1010/2005, voltadas para consolidar o perfil profissional do engenheiro e as citadas resoluções do CONFEA mais voltadas especificamente 
para o profissional engenheiro de produção. Estas abordaram, entre os diversos tópicos que definiu suas respectivas competências dessa profissão, o termo hoje modernamente denominado de engenharia legal. Esta compreende todas as atividades relacionadas a solucionar problemas jurídicos que dependam de conhecimentos técnicos os quais nem sempre estão relacionados às atividades de advogados e magistrados; isso perfaz a função do perito judicial em matéria de engenharia.

Contudo, os preceitos éticos devem ,obrigatoriamente, ser parte constante do profissional nos mais diferentes tipos de abordagem e explanações para solucionar os mais diversos tipos de problemas sob a responsabilidade do engenheiro de produção. O engenheiro deve desenvolver a compreensão global do processo produtivo com a apreensão do saber tecnológico com o ato de desenvolver, coordenar e motivar o trabalho em equipe, e dos princípios sociais e jurídicos que norteiam o trato com o ser humano. A figura 1 apresenta um esquema de conhecimentos básicos que um engenheiro, no caso desse trabalho, de produção deve possuir para gerenciar a equipe de colaboradores.

Figura 1: representação esquemática do rol de competências do engenheiro de produção. 


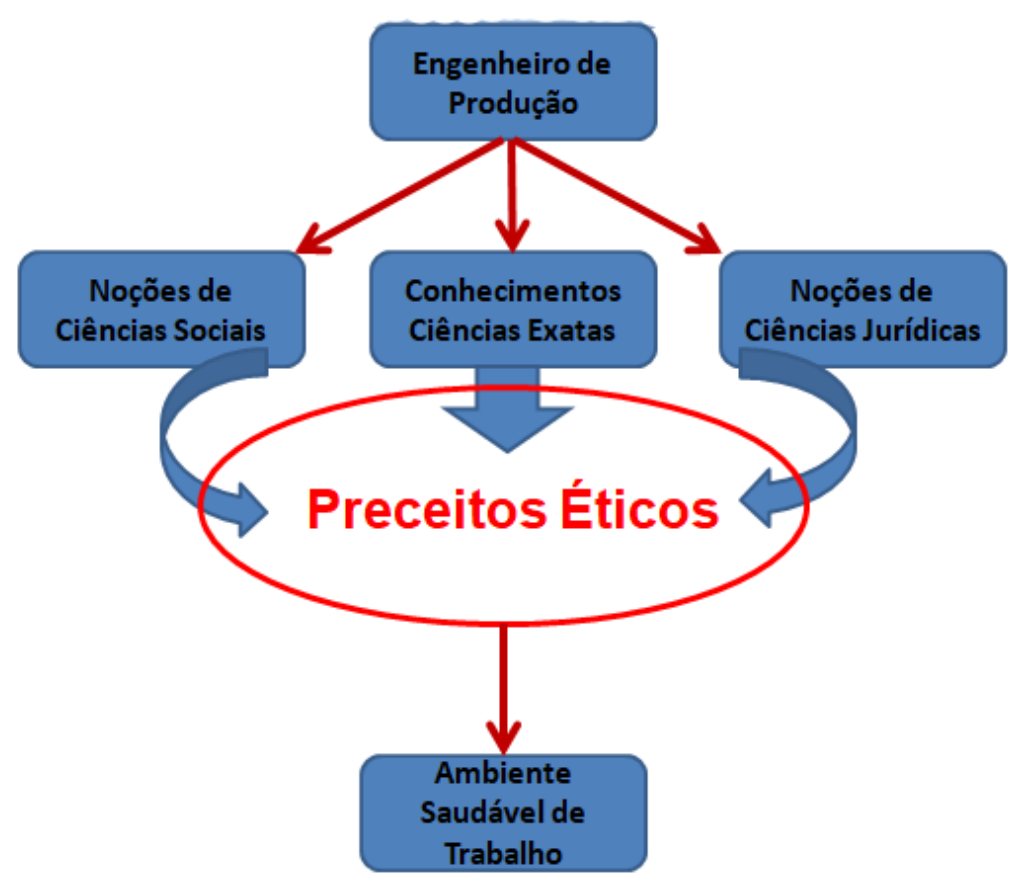

Fonte: Autores

Ainda se observa, por meio da representação esquemática da figura 1, que o engenheiro de produção agregaria maior autonomia intelectual e juridicamente interpessoal, devido a sua própria responsabilidade civil, diante das atribuições técnicas e éticas que envolvem essa profissão. Manter o ambiente saudável de trabalho não é tarefa fácil, pois não depende somente de si. Mas a manutenção de uma equipe coesa e focada promove o crescimento e desenvolvimento de todos para atingir as metas estabelecidas. Este profissional deve também ser capaz de tomar decisões e resoluções mediante as situações que normalmente surgem implacavelmente nas relações profissionais nos mais variados níveis hierárquicos.

No que tange à formação profissional do indivíduo como engenheiro de produção, as Resoluções Conselho Nacional de Educação (CNE) e da Câmara de Educação Superior (CES) do Ministério da Educação: CNE/CES 11/03/2002 e CNE/CES 02/04/2019 forneceram as determinações legais a respeito das bases curriculares para criação dos cursos nessa área. 
O mercado de trabalho, atualmente, precisa de profissionais generalistas com visão holística, diante dessa vastidão de informações e necessidades e demandas que surgem a cada instante. Modelos prontos e estáticos de procedimentos que o engenheiro de produção deve seguir frente aos colaboradores, atualmente, não se concebem, mas sim, estes devem seguir as bases das regras gerais preconizadas e aplicadas às diferentes realidades e possibilidades de gerenciamento consolidadas no rol de possíveis disciplinas, básicas e específicas, que podem integralizar o currículo do curso de engenharia de produção, de acordo com o público alvo a que se destina.

Cabe ressaltar, ainda, que a engenharia sempre foi considerada a mola mestra do crescimento econômico e dos avanços tecnológicos; desde meados do século XVIII com a Revolução Industrial iniciada na Inglaterra (HOBSBAWM, 2016). Contudo, as diferentes áreas do conhecimento estão cada vez mais interligadas e se completam tanto na construção da personalidade da pessoa humana quanto na construção do trato profissional entre os colaboradores. A conscientização do papel do ser humano em sociedade e os tratos sociais advêm de preceitos culturais antropológicos. Sir Edward Burnett Tylor, um dos fundadores da antropologia moderna, definiu no século XIX a cultura como um conjunto complexo de conhecimentos, crenças, leis e costumes que alicerçavam a ciência e tecnologia (LARAIA, 2014). De acordo com Wright Mills (2009) o fazer da ciência constituiria em um "artesanato intelectual", que se consolidaria no princípio da prática social:

\footnotetext{
“O conhecimento é uma escolha tanto de um modo de vida quanto de uma carreira; quer o saiba ou não, o trabalhador intelectual forma-se a si próprio à medida que trabalha para o aperfeiçoamento de seu ofício; para realizar suas próprias potencialidades, e quaisquer oportunidades que surjam em seu caminho, ele constrói um caráter que tem como núcleo as qualidades de um bom trabalhador. Isso significa que deve
} 
aprender a usar sua experiência de vida em seu trabalho intelectual: examiná-la e interpretá-la continuamente" (Wright Mills 2009).

\section{PSICOLOGIA JURÍDICA APLICADA AO AMBIENTE CORPORATIVO}

O termo psicologia se traduz em psique (mente) + logia (estudo) que, juntos, descrevem o estudo dos processos mentais; desejos, percepções, motivações e ações decorrentes a quaisquer tipos de pressões derivadas de estresses mediantes a situações conflitantes (HOUAISS, 2009).

Todo ser humano é composto por um conjunto infindo de sentimentos diferentes e que reage de modo totalmente adverso um do outro; principalmente quando colocado em situações como estresse, pressão, finanças e etc. De acordo com Fiorelli e Mangini (2019) o ser humano é capaz de ser agente e paciente nas mais diferentes situações em que pode ser submetido. A própria pessoa reserva em si mesma a opção de ir de encontro à autorrealização, sem se descuidar dos limites que as realidades social, econômica e cultural impõem. A personalidade do indivíduo é integrada por sistemas psicológicos responsáveis por padrões de comportamento, pensamento, sentimento e emoção que compõem as características únicas de um indivíduo (HEIDEGGER, 2013 e BOFF, 2014).

A ética é construída por uma sociedade com base nos valores históricos e culturais. Todas as ações do homem são regidas por códigos universais, movidos pela ética e pela moral.

Os termos: ética e moral possuem origens etimológicas diversas uma da outra. Ética vem do Grego "ethos" e se traduz em "modo de ser" ou "caráter". Enquanto "moral" tem origem no termo latino "morales" e se traduz em "relativo aos costumes" (HOUAISS, 2009). No contexto lúdico, tais termos possuem finalidades semelhantes. Pois são os pilares da conduta do homem, uma vez que edificam o seu caráter, virtude e definem o modo de agir e o comportamento deste em sociedade. 
Mediante tais características, a moral e a ética constituem uma das bases da promoção e do respeito aos Direitos Humanos, pois emolduram um olhar crítico e atento do cotidiano de um membro com relação aos demais, independente do grau hierárquico em uma equipe de trabalho. Tais conceitos tornam-se sobrepujantes no respeito à pluralidade, ao gênero, a diversidade de hábitos, costumes e sentimentos que envolvem todos os colaboradores que se dispuseram a desenvolver suas atividades coletivamente por força do serviço que ora sejam designados (OLIVEIRA JÚNIOR, 2010).

Segundo Melo (2006), Ética e Direito polarizam grande carga emocional devido à emotividade que trazem consigo. A emotividade se incorporaria ao patrimônio espiritual, e, isso dificultaria o acesso ao mínimo de racionalidade e de objetividade que se permitiria fugir de proposições meramente emotivas. A ética, enquanto princípio dominante na formação da consciência jurídica, está presente no julgamento axiológico de toda norma jurídica de caráter atributivo. Essa diretriz deontológica permitiria a existência de uma política jurídica para a construção do direito. Ainda segundo esse autor a palavra ética é empregada nos meios acadêmicos com três acepções distintas:

1) Neste caso se faz referência a teorias que têm como objeto de estudo o comportamento moral, ou seja, consiste na teoria que pretende explicar a natureza, fundamentos e condições da moral, relacionando-a com necessidades sociais dos homens. Nessa acepção, o entendimento de que o fenômeno moral pode ser estudado racional e cientificamente por uma disciplina que se propõe a descrever as normas morais ou mesmo, com o auxílio de outras ciências, ser capaz de explicar valorações comportamentais.

2) Consiste em considerá-la uma categoria filosófica e mesmo parte da Filosofia, a qual se constituiria em núcleo especulativo e reflexivo sobre a complexa fenomenologia da moral na convivência humana. 
3) Trata-se, nesse caso, da conduta esperada pela aplicação de regras morais no comportamento social, o que se pode resumir como qualificação da conduta do homem enquanto ser em situação. Esse caráter normativo de Ética a coloca em íntima conexão com o Direito. Nessa visão, os valores morais dariam o balizamento do agir e a Ética seria assim a moral em realização, pelo reconhecimento do outro como ser de direito, especialmente de dignidade. Esta terceira possibilidade do uso da palavra Ética guarda conexão com enunciado proposto por Max Weber como ética social ou de responsabilidade. É o agir consciente daquele que sabe das consequências de suas escolhas atitudinais, especialmente quando as normas éticas estão formando o núcleo axiológico da atributividade jurídica.

Diante a importância dos conceitos éticos inseridos em um contexto histórico, estes estão inclusos no processo da secularização da sociedade. A ética das relações demonstra a importância de um consenso tácito entre os cidadãos acerca do que é essencialmente essa perfeição impossível entre a moral civil entre grupos sociais naturais aos quais pertencemos: uma categoria profissional, uma cidade, uma nação unitária.

Conforme a definição de ética cívica por Adela Cortina (2005), esta autora conceituou como um conjunto de valores e normas que os membros de uma sociedade pluralista compartilham, não importa quais sejam as suas concepções de vida boa, ou os seus projetos de felicidade. A ética cívica consiste em um conjunto de exigências mínimas compartilhadas por cidadãos que defendem variadas concepções éticas ou religiosas; simplesmente pelo bem viver em sociedade, e, por conseguinte também em ambientes de trabalho. Ou seja, é um mínimo moral comum de uma sociedade secular e pluralista que significa dizer que a ética cívica é a convergência moral das diversas opções morais de uma 
sociedade. Vista como um novo paradigma capaz de representar uma alternativa da cultura ocidental.

Historicamente quando se depara com a psicologia empregada no pleno exercício do direito quanto ciência, há o termo "Psicologia Jurídica”. A Psicologia Jurídica segundo o autor Mira Y López (2018), a define como a psicologia aplicada ao melhor exercício do Direito. Ela propiciaria o entendimento do comportamento humano e o funcionamento do aparelho psíquico, suas alterações, seus transtornos e patologias, auxiliando a compreensão da conduta de indivíduos em diversas situações; como por exemplo, aquelas limítrofes do comportamento humano sob uma carga emocional no ambiente de trabalho, que também perpassa as questões jurídicas.

De acordo com os autores Fiorelli e Mangini (2019) a historicidade que abarca a confluência da psicologia com a justiça começou notoriamente a ser registrada a partir do século XIX quando os médicos eram chamados para auxiliarem a desvendar o enigma de certos delitos graves. Tais comportamentos pareciam originar-se de complexas conexões oriundas dos estados emocionais e/ou dos componentes orgânicos que fugiam ao controle do próprio indivíduo. Assim, psicologia jurídica fundamentou-se a partir de várias perspectivas científicas que a auxiliaram na edificação de uma análise comportamental do indivíduo, tais como: sociais, biológicas, etológicas, econômicas; e a própria perspectiva psicológica que especialmente em sua base abrigaria uma grande oscilação entre o conhecimento científico e o que seria o viés ideológico. A psicologia jurídica trata de uma especialidade que consiste na aplicação de conhecimentos psicológicos ligados às questões da área jurídica, constituindo em uma interface da psicologia com o Direito (GONÇALVES e BRANDÃO, 2018).

Quando se trata da maneira de proceder das pessoas em direção às ações emitidas ou recebidas, tomadas de decisões, principalmente nas 
organizações, estas entrelaçam com uma questão delicada e que envolve, primordialmente, à questão comportamental dentro de equipes de trabalho.

O psicológico do colaborador, tanto ao emitir quanto ao receber uma proposição hierarquicamente superior e manter um comportamento ético e juridicamente aceitável, consiste no grande exercício de convivência e sobrevivência nas corporações. O lidar com tais situações adversas permite tanto engenheiro de produção quanto ao colaborador desenvolver vários tipos de percepções da realidade no ambiente de trabalho. Tecnicamente a sinergia necessária nesses casos nem sempre estariam descritas na literatura, manuais ou através de outros veículos de comunicações e acessíveis aos colaboradores; mas sim da convivência rotineira da equipe e da capacidade de emitir e receber elogios e críticas quando necessárias para extrair a melhor performance profissional.

\section{COMUNICABILIDADE: CAUSAS E EFEITOS NA TOMADA DE DECISÃO}

A comunicação é uma necessidade básica do indivíduo por ser gregário de natureza humana (HUME, 2009) e se traduz no canal pelo qual os padrões de vida e cultura são transmitidos para que um indivíduo viva em sociedade (SANTOS, 2018). Ela promove o bem-estar, autoconfiança e respeito pela diversidade à medida que o sujeito se reconhece no outro e se percebe enquanto parte do ambiente. Diante disso, a comunicação colabora para a promoção do trato emocional, pois possui raiz no desenvolvimento e controle corporal para uma convivência harmônica (TEIXEIRA e PEDROSO, 2019).

Uma comunicação eficaz altera comportamentos, pensamentos e procedimentos no ambiente de trabalho (NEIVA, 2018). O ato de comunicar exerce um papel determinante tanto no nível de desempenho quanto de qualidade dos serviços prestados, pois conscientiza os colaboradores de sua 
importância na engrenagem de empresa. O que não se é comunicado é visto como inexistente; logo, a comunicação institucional deve ser profícua e transmitida de modo que se busque fomentar e assegurar a verbalização entre emissor e receptor para que não gere dúvidas e ambiguidades (CRUZ JUNIOR, 2019).

Os profissionais que possuem cargo hierárquicos superiores devem se comunicar com o propósito de se fazer entender e convencer os colaboradores a comprarem a ideia. Mediante um conceito amplo e moderno, o profissional tem que proporcionar uma comunicação clara e precisa, simultaneamente com decisões rápidas, visão e ação integral, iniciativa própria e informação plena da situação corporativa (SANTOS, 2018).

Segundo Porto e Bandeira (2006), a tomada de decisão consistiria em um processo necessário a solucionar um dado problema, em que diferentes alternativas seriam propostas e teriam como finalidade a geração de melhores resultados para as organizações como um todo. Diante disso, tais ações se transformariam em uma das mais importantes tarefas desempenhadas pelos administradores e líderes de equipe, no qual se insere o engenheiro de produção.

A finalização de todo o processo decisório ainda esbarraria em certos limites no que tange aos aspectos de como escolher o que fazer, com quem e quando (YU e SOUSA, 2012). Não obstante também deveria ser posto neste rol de procedimentos, alguns menos agradáveis, tais como: correções de procedimentos e atividades realizadas pelos colaboradores, realocação deles quando a performance encontrar-se abaixo da esperada frente aos demais, e até o seu respectivo desligamento.

Nas ações corporativas em decorrências da necessidade de não se perder tempo, mercado e qualidade dos bens produzidos, todos os aspectos da tomada de decisão devem ser contemplados, principalmente os psicológicos, éticos e morais. 
Solino e El-Aouar (2001) abordaram que as habilidades dos colaboradores dever-se-iam ser incentivadas a aflorar à criatividade e o talento assim como a delegação de responsabilidades no processo decisório, o que permitiria àqueles profissionais com cargos de gerencia e supervisão tal como os engenheiros de produção podem assumir e desenvolver uma inter-relação entre os membros que a transformaria em uma vantagem competitiva desta.

Segundo Teixeira, Fernandes e Almeida et al. (2014) o processo de tomada de decisão, principalmente aquele nos quais os líderes de equipe fossem testados constantemente, envolveria um equilíbrio psicológico que estes membros deveriam possuir; e este se traduziria em um controle emocional, intelectual e profissional, necessários a perfeita harmonia frente à equipe de colaboradores.

Ainda segundo estas autoras a inteligência emocional influenciaria eficazmente tanto no campo individual quanto no profissional, impactando no sucesso da organização como um todo. Diante de tal premissa, esse conjunto de atitudes seria muito valorado nas atuais organizações contemporâneas do mundo capitalista, como um fator primordialmente crítico de se alcançar o sucesso ou o fracasso. Isso ocorreria caso tal capacidade de tomada de decisão não contemplasse uma expertise e uma comoção nos liderados, diante das agruras do gerenciamento das atividades necessárias e pertinentes às ordens técnicas e juridicamente tão bem apreciadas e estimadas.

De acordo com Mazurkiewicz (2018) haverá grandes mudanças na forma de organização da sociedade, a começar pelas relações de trabalho. Isso refletiria nas inter-relações do ambiente de trabalho no qual se votaria em uma sociedade de criadores, com colaboradores desenvolvendo mais de um projeto simultaneamente e não uma estrutura hierarquizada de superespecialistas. 


\section{Considerações Finais}

As pessoas vivem um novo paradigma de relacionamentos mais complexos, que demandam da sociedade civil, organizada e dos poderes constituídos de respostas mais democráticas, mais participativas e mais efetivas para as demandas da sociedade. A sociedade vive um momento de compartilhamento de interesses e ações em benefícios mútuos. Não se pode negar o salto civilizatório quando a própria sociedade assume a responsabilidade pela condução, ou pelo menos pela participação na construção do seu próprio destino.

Neste trabalho, os princípios que fundamentaram a ética e a psicologia jurídica foram utilizados para corroborar na plenitude de ações que o engenheiro de produção deve identificar nos membros da equipe sob sua liderança e, principalmente, a sua própria; mediante as situações de conflitos, estresse emocional, agressividade e até mesmo a violência nos mais diferentes tipos e intensidades que podem ocorrer no ambiente de trabalho.

Todos os colaboradores em uma equipe de trabalho já experimentaram uma sensação de estar diante de um problema extraordinariamente complexo e aparentemente insolúvel; contudo, se manter dentro dos padrões éticos e morais por mais que sejam testados ao extremo permite ao mesmo ter um controle psicológico e juridicamente aceitável nos ambientes corporativos. Principalmente no que tange ao ambiente de trabalho que se materializa sob um regime de intensa carga emocional, privações e dificuldades, tais como: adaptação, treinamento e metas de produtividade a serem alcançadas.

A interação entre as diversas áreas está em permanente movimentação e autorreformulação no estudo de fenômenos complexos que envolvem o comportamento humano e estão mutuamente imbricadas numa empreitada 
transdisciplinar. A psicologia jurídica, nesse caso, vem adicionar um lócus de percepções nas ações-reações que o engenheiro de produção deve ficar atento a si mesmo e aos demais para se atingir as metas preconizadas, e se manter equilibrado no ambiente de trabalho.

As estruturas corporativas hierarquizadas, na qual a performance profissional é avaliada sistematicamente, podem levar ao limiar do comportamento ético, moral e juridicamente aceitável devido as pressões impostas pelo conjunto de atribuições que se espera do engenheiro de produção.

O processo de comunicação é extremamente importante no círculo profissional, pois, se este apresentar ambiguidades, falhas ou gerar ruídos desgastantes que conduzirão a implicações legais, pode-se chegar até a judicialização nas atividades profissionais.

Diante disso, o equilíbrio comportamental é extremamente saudável para manter a homogeneidade e a coesão dos colaboradores à realização das diferentes tarefas e desafios. Inegavelmente a observação comportamental deve ser realizada não somente pelo engenheiro, mas por uma equipe multiprofissional principalmente formada por: psicólogo, enfermeiro, médico e operadores do direito; que começaria desde o processo seletivo (seleção, exames de saúde ocupacional, admissão, recursos humanos, contratação e cursos de capacitação) até o processo demissional.

\section{Referências}

BOBBIO, Norberto. O Futuro da Democracia. São Paulo: Ed. Paz e Terra, 8a ed., 304p., 2009.

BOFF, Leonardo. Ética e Moral: a busca dos fundamentos. Petrópolis: Ed. Vozes, 9a ed., 134p., 2014.

CORTINA, Adela. Ética Civil Y Religión. Madrid: Ed. PPC, 4aㅡ ed., 128 p., 2005. 
CRUZ JUNIOR, Sidmar J. A importância da Comunicação nas Instituições Públicas. Revista Científica Multidisciplinar Núcleo do Conhecimento. Ano 4, 6aㅡ ed., v. 10, p. 49-60, jun., 2019.

CUCONATO, Paulo. A Mediação e a Descrição do seu Caminhar no Processo Legislativo. Rio de Janeiro: Dissertação de Mestrado. UNESA (Universidade Estácio de Sá), 212p., 2016.

DECRETO № 23.569 de 11 de Dezembro de 1933.

FIORELLI, José O. e MANGINI, Rosana C. R. Psicologia Jurídica. São Paulo: Ed. Gen Atlas S.A., 10a ed., 446p., 2019.

GONÇALVES, Hebe S. e BRANDÃO, Eduardo P. Psicologia Jurídica no Brasil. Ed. Nau, 3a ed., 3a reimp., 351p. 2018.

HEIDEGGER, Martin. Ontologia: (Hermenêutica da faticidade). Petrópolis: Ed. Vozes, 2a ed., 134p., 2013.

HOBSBAWM, Eric J. A Era das Revoluções 1789-1848. Rio de Janeiro: Paz e Terra, 1ae ed., p. 79, 2016.

HOUAISS, Antônio. Dicionário Houaiss da Língua Portuguesa. Rio de Janeiro: Ed. Objetiva Ltda., 1ae ed., 1986p., 2009.

HUME, David. Tratado da Natureza Humana. São Paulo: Ed. Unesp, 2a ed., 759p., 2009.

LARAIA, Roque de Barros. Cultura (Um Conceito Antropológico). Rio de Janeiro: Ed. Zahar, 26a reimp., 117p., 2014.

LEI № 5.194, de 24 de Dezembro de 1966.

MAZURKIEWICZ, Ligia Zotini. Palestra: "Um dia em 2037 - o futuro do trabalho e das relações". VI FONAMEC. Revista: Justiça e Cidadania, abr., p. 1012, 2018.

MELO, Osvaldo Ferreira de. Ética e Direito. Revista: Novos Estudos Jurídicos, v. 11, n. 1, pág. 35-39, ISSN 2175-0491, 2006.

MINISTÉRIO DA EDUCAÇÃO: Resolução CNE/CES 11/03/2002

MINISTÉRIO DA EDUCAÇÃO: Resolução CNE/CES 02/04/2019 
MIRA Y LOPEZ, Emilio. Manual de Psicologia Jurídica. Campinas: Ed. Servanda, 2a ed., 464p., 2018.

NEIVA, Filipa. Comunicação das Organizações: um olhar sobre a importância da comunicação interna. Lisboa: Revista Media \& Jornalismo, nov., v. 18, n. 33, 2018.

OLIVEIRA JÚNIOR, José A. de (Org.). Cultura e Prática dos Direitos Fundamentais. Rio de Janeiro: Ed. Lumen Juris, 1aed., 160p., 2010.

PORTO, Maria A. G. e BANDEIRA, Anselmo A. O Processo Decisório nas Organizações. Anais: XIII SIMPEP, Bauru, nov., p. 1-11, 2006.

RESOLUÇÃO CONFEA no 218 de 29 de junho de 1973.

RESOLUÇÃO CONFEA no 235 de 09 de outubro de 1975.

RESOLUÇÃO CONFEA no 288 de 07 de dezembro de 1983.

RESOLUÇÃO CONFEA no 1010 de 22 de agosto de 2005.

SANTOS, Rosineia O. A Importância da Comunicação no Processo de Liderança. Santos: Revista de Administração em Saúde, jul.-set., v. 18, n. 72, 2018.

SOLINO, Antônia S.; El-AOUAR, W. A. O processo de tomada de decisões estratégicas: entre a intuição e a racionalidade. Caderno de Pesquisas em Administração, São Paulo, v. 08, n. 3, jul./set. 2001.

TEIXEIRA, Aline V. e PEDROSO, Sandra M. D. Desenrole-se: a melhoria da comunicação verbal através da expressão corporal. Ponta Grossa: Anais da Jornada Científica dos Campos Gerais, v. 17, 2019.

TEIXEIRA, Andréia R. A.; FERNANDES, Priscila S.; ALMEIDA, Luciana P. M. et. al. A Influência da Inteligência Emocional na Tomada de Decisão Gerencial. Anais: XI Simpósio de Excelência em Gestão e Tecnologia (SEGeT), Resende, out., 2014.

YU, Abraham S. O. e SOUSA, Willy H. Planejando a Tomada de Decisões: a Abordagem das Meta-Decisões. Anais: XXXVI encontro da ANPAD, Rio de Janeiro, set., p. 1-16, 2012.

WRIGHT MILLS, Charles. Sobre o Artesanato Intelectual e Outros Ensaios. Rio de Janeiro: Zahar, p. 22, 2009. 